\title{
PERMODELAN SIMPANG EXIT TOLL KEBAKKRAMAT DENGAN SISTEM FIXED TIME CONTROLLER DAN SEMI ACTUATED CONTROLLER MENGGUNAKAN PROGRAM SIMULASI PTV VISSIM
}

\author{
Irsa Laksita Dewi ${ }^{1)}$ \\ 1) Mahasiswa Fakultas Teknik, Prodi Teknik Sipil, Universitas Sebelas Maret \\ Jl. Ir. Sutami No. 36A, Kentingan, Surakarta 57126; Telp. (0271) 647069, Fax 634524 \\ Email: $\underline{\text { sasalaksita@student.uns.ac.id }}$
}

\begin{abstract}
To ensure the usefulness of toll roads, conscientious planning is needed from all aspects, the example is the performance of intersection that leads to the toll road or commonly called the exit toll intersection. Therefore, each exit toll intersection must have maximum performance, so it doesn ' traffic problems for the surrounding transportation. In this study, an assessment of the Kebakekramat exit toll intersection was conducted using PTV VISSIM. This study was conducted to find out about the performance of the Kebakkramat exit toll intersection. The variable that is taken into account in the calibration process is the volume of traffic flow which is calculated from the traffic counting survey and tested by the Geoffrey E. Havers method. In addition, validation is also carried out on the LV travel time, the queue length in the field which is tested by the t test method. The results showed that the Semi Actuated Controller system with normal phase control had no significant effect on improving the performance of the Kebakekramat Exit Toll intersection because there were vehicles traveling from the minor road.
\end{abstract}

Keywords: Kebakeramat Exit Toll Intersection, GEH Statistical Test, PTV VISSIM, Semi Actuated Controller

\begin{abstract}
Abstrak
Untuk menjamin kebermanfaatan jalan tol, maka dibutuhkan perencanaan yang matang dari segala aspek, salah satunya kinerja persimpangan yang mengarah ke tol atau biasa disebut dengan simpang exit toll. Oleh karena itu, setiap persimpangan exit toll haruslah memiliki kinerja yang maksimal, sehingga tidak menimbulkan permasalahan lalu lintas bagi keberjalanan transportasi disekitarnya. Pada penelitian ini dilakukan pengkajian simpang exit toll Kebakkramat menggunakan PTV VISSIM. Pengkajian ini dilakukan untuk mengetahui bagaimana kinerja dari simpang exit toll Kebakkramat. Variabel yang diperhitungkan dalam proses kalibrasi yaitu volume arus lalu lintas yang dihitung dari survey traffic counting dan diuji dengan metode Geoffrey E. Havers. Selain itu juga dilakukan validasi pada waktu perjalanan LV, panjang antrian di lapangan yang diuji dengan metode uji t. Hasil penelitian menunjukkan sistem Semi Actuated Controller dengan jenis pengatiran fase normal tidak berpengaruh signifikan terhadap penigkatan kinerja Simpang Exit Toll Kebakkramat karena terdapat kendaraan yang melaju dari jalan minor.
\end{abstract}

Kata Kunci: PTV VISSIM, Semi Actuated Controller, Simpang Exit Toll Kebakkramat, Uji Statistik GEH,

\section{PENDAHULUAN}

Dewasa in pembangunan jalan tol senantiasa berkembang untuk mengimbangi laju pertumbuhan serta kebutuhan fasilitas transportasi yang memadahi. Salah satu tol yang ada di wilayah Jawa Tengah adalah Tol Solo-Kertosono atau kerap disebut Tol Soker. Kenyamanan penggunaan tol tidak hanya tentang lintasan aspal, maupun tarif, namun juga akses keluar masuk pada Exit Toll. Apabila terdapat kendala seperti antrian, atau akses yang sulit pada Exit Toll, maka akan menurunkan keefektifan dan keefisienan kinerja jalan tol itu sendiri. Pertemuan antara ruas jalan tol dengan ruas jalan umum disebut dengan simpang Exit Toll, karena adanya perbedaan volume lalu lintas dari kedua ruas tersebut, maka terbentuklah potensi terjadinya permasalahan pada simpang Exit Toll.

Untuk mempermudah serta memperjelas analisis kinerja Simpang Exit Toll Kebakkramat, maka digunakanlah program simulasi PTV VISSIM. Program simulasi PTV VISSIM merupakan perangkat lunak aliran mikroskopis yang digunakan untuk kegiatan permodelan lalu lintas. Dalam hal ini, program simulasi PTV VISSIM dapat memodelkan kondisi lapangan secara keseluruhan dalam bentuk simulasi 2D dan 3D. Untuk mendapatkan hasil yang akurat dan mendekati kenyataan maka dibutuhkan proses kalibrasi dan validasi pada model yang dibuat 


\section{DASAR TEORI}

\section{Simpang}

Simpang merupakan area konflik arus lalu lintas yang rawan akan kemacetan, karena merupakan bertemunya dua ruas jalan atau lebih. Simpang dibagi menjadi empat jenis berdasarkan pola pergerakannya, yaotu berpotonga, bergabung, berpisah, dan berjalinan. Kemudian menurut tingkat arus lalu lintasnya, simpang dibagi menjadi simpang tanpa prioritas, simpang dengan prioritas, simpang dengan bundaran, simpang dengan lampu lalu lintas, dan yang terakhir simpang tak sebidang.

\section{Lampu Lalu Lintas}

Lampu lalu lintas atau lebih lengkapnya Alat Pemberi Isyarat Lalu Lintas (APILL) merupakan lampu yang terletak di sisi sebelah kanan dan kiri kaki simpang yang terdiri dari rangkaian lampu berwarna merah , kuning, dan hijau yang digunakan sebagai pengendali dan pengatur arus lalu lintas. Sistem pengaturan lampu lalu lintas terbagi menjadi 3 sistem (Budi Yulianto, 2012) yaitu Fixed Time Controller (FTC), Vehicle Actuated Controller (VAC), dan Demand Responsive (DRC).

\section{Kinerja Simpang Bersinyal}

Kemampuan kinerja simpang dinilai dari beberapa faktor, yaitu tingkat pelayanan, kapasitas, derajat kejenuhan, tundaan, panjang antrian, waktu siklus, arus lalu lintas, hambatan samping, dan kecepatan.

\section{Waktu Siklus Simpang Bersinyal}

Waktu siklus adalah durasi perubahan sinyal lengkap yaitu antara dua awalan hijau yang berurutan pada fase yang sama, yaitu Membatasi Pergerakan, Mengizikan Pergerakan, Memisahkan Pergerakan, Awal yang Terlambat (Late Start), Fase Khusus Belok Kanan.

\section{Program Simulasi PTV VISSIM}

Pada penelitian kali ini, digunakan program simulasi PTV VISSIM . Program ini merupan mikrosimulasi yang memiliki kemampuan untuk melaksanakan analisa, perencanaan, serta optimalisasi kinerja lalu lintas.

\section{Kalibrasi dan Validasi PTV VISSIM}

Kalibrasi merupakan proses penyesuaian parameter yang dilakukan beberpakali hingga nilai yang dihasilkan dari model simulasi sesuai dengan nilai yang didapatkan dari hasil penghitungan di lapangan. Pada penelitian kali ini jumlah arus lalu lintas setiap kaki simpang ditetapkan sebagai parameter. Kemudian untuk validasi sendiri merupakan tahapan yang dilakukan untuk mengetahui apakah model simulasi lalu lintas dapat merepresentasikan keadaan lalu lintas realita atau tidak. Model simulasi dinyatkan valid apabila memenuhi persyaratan jika keluaran data model mendekati data observasi lapangan. Pada penelitian ini, waktu tempuh perjalanan atau Travel Time, dan panjang antrian kendaraan dijadikan sebagai variabel, serta dihitung menggunakan rumus:

\section{Perbedaan Relatif (Relative Difference)}

Merupakan metode pemghitungan yang dilakukan dengan cara membandingkan nilai perbedaan mutlak dengan nilai yang didapatkan dari hasil observasi lapangan. Sedangkan, nilai perbedaan mutlak sendiri merupakan hasil pengurangan dari nilai yang didapatkan dari model simulasi dengan nilai hasil observasi.

$$
\text { Perbedaan } \operatorname{Re} \text { latif }=\frac{(\text { NilaiModel }- \text { NilaiObservasi })}{\text { NilaiObservasi }} \ldots \ldots \ldots \ldots \ldots . . . . . .[1]
$$

\section{Statistik GEH (Geoffrey E. Havers)}

Merupakan rumus persamaan yang menentukan kesesuaian antara jumlah arus lalu lintas dengan membandingkan hasil survey observasi lapangan dengan model simulasi.

$$
\begin{aligned}
& G E H=\sqrt{\frac{\left(q_{m}-q_{o}\right)^{2}}{0,5 x\left(q_{m}+q_{o}\right)}} \\
& \text { dengan rincian } \\
& \mathrm{q}_{\mathrm{m}}=\text { arus lalu lintas hasil Model } \\
& \text { qo = arus lalu lintas hasil Observasi }
\end{aligned}
$$


Tabel 1. Kesimpulan perhitungan rumus statistic GEH (Geoffrey E. Havers)

\begin{tabular}{ll}
\hline Nilai GEH & Keterangan \\
\hline GEH $<5,0$ & Diterima \\
$5,0 \leq \mathrm{GEH} \leq 10,0$ & Peringatan : Kemungkinan ditolak \\
$\mathrm{GEH}>10,0$ & Ditolak \\
\hline
\end{tabular}

3. Independent Sample T-test

Merupakan pengetesan yang membandingkan hasil panjang antrian model obserfasi dengan model simulasi. Karena jenis data sama, maka menggunakan rumus Polled V ariant:

$$
t=\frac{\bar{X}_{1}-\bar{X}_{2}}{\frac{\left(n_{1}-1\right) S_{1}^{2}+\left(n_{2}-1\right) S_{2}^{2}}{n_{1}+n_{2}+2}\left(\frac{1}{n_{1}}+\frac{1}{n_{2}}\right)}
$$

Dengan :

$\mathrm{X}_{1}=$ Rerata sampel 1

$\mathrm{X}_{2}=$ Rerata sampel 2

$\mathrm{S}_{1} \quad=$ Deviasi Standar sampel 1

$\mathrm{S}_{2} \quad=$ Deviasi Standar sampel 2

$\mathrm{S}_{1}{ }^{2}=$ Variasi sampel 1

$\mathrm{S}_{2}{ }^{2}=$ Variasi sampel 2

$\mathrm{n}_{1} \quad=$ Jumlah data sampel 1

$\mathrm{n}_{2} \quad=$ Jumlah data sampel 2

Hasil uji dikatakan diterima apabila menunjukkan jika $\mathrm{T}_{\text {hitung }}<\mathrm{T}_{\text {tabel }}$ (two-tailed) serta nilai dari $\mathrm{P}($ two-tailed) $>0,05$.

\section{METODE PENELITIAN}

\section{Pengumpulan Data}

Dalam proses pembuatan model simulasi, diperlukan data yang digunakan sebagai input. Pada penelitian kali ini, penulis menggunakan dua jenis data yaitu data priimer dan sekunder. Data primer meruapakan data yang diperoleh melalui pelaksanaan survey langsung di lapangan, yang meliputi :

1. Pencacahan lalu lintas

2. Kecepatan kendaraan

3. Waktu perjalanan

4. Panjang antrian

5. Waktu siklus lampu lalu lintas

6. Geometrik simpang dan ruas jalan

Data sekunder adalah data yang diperoleh melalui studi literatur, atau media perantara lainnya. Pada penelitian kali ini, penulis menggunakan data sekunder berupa foto udara Google Maps yang dipergunakan sebagai latar belakang proses permodelan pada PTV VISSIM.

\section{Analisis Data}

Setelah menghasilkan model simulasi yang sesuai dengan data yang diperolah, maka dilakukan analisis yang nantinya akan menghasilkan beberapa parameter, diantaranya yaotu panjang antrian, tundaa, serta waktu perjalanan.

\section{Kalibrasi dan Validasi Base Model}

Proses kalibrasi dan validasi menggunakan parameter yang sebelumnya telah pernah diujikan di beberapa penelitian, seperti Lateral behavior, Desired position of free flows, Default behavior when overtaking vehicle on the same lane, Following behavior, Average standstill distance yang terdapat dalamm menu Driving behavior.

\section{HASIL DAN PEMBAHASAN}

Untuk mengetahui apakah model simulasi dapat merepresentasikan keadaan eksisting atau tidak, maka dilakukan kalibrasi dengan menggunakan uji statistic GEH guna menghitung selisih jumlah arus lalu lintas model dengan hasil observasi setiap simpang. 
Tabel 2. Hasil uji GEH pada arus lalu lintas peak dan off-peak

\begin{tabular}{|c|c|c|c|c|c|c|c|c|c|}
\hline \multicolumn{5}{|c|}{ Jam Puncak } & \multicolumn{5}{|c|}{ Jam Tidak Puncak } \\
\hline Lokasi & Rata-rata & $\begin{array}{c}\mathrm{q}- \\
\text { Obervasi }\end{array}$ & $\begin{array}{l}\text { Nilai } \\
\text { GEH }\end{array}$ & Keterangan & Lokasi & Rata-rata & $\begin{array}{c}\mathrm{q}- \\
\text { Obervasi }\end{array}$ & $\begin{array}{l}\text { Nilai } \\
\text { GEH }\end{array}$ & Keterangan \\
\hline 1 & 3618 & 3638 & 0,33 & Diterima & 1 & 2141 & 2132 & 0,19 & Diterima \\
\hline 2 & 186 & 185 & 0,07 & Diterima & 2 & 216 & 209 & 0,48 & Diterima \\
\hline 3 & 3585 & 3561 & 0,40 & Diterima & 3 & 2056 & 2040 & 0,35 & Diterima \\
\hline 4 & 2330 & 2321 & 0,19 & Diterima & 4 & 1779 & 1759 & 0,48 & Diterima \\
\hline 5 & 175 & 173 & 0,15 & Diterima & 5 & 224 & 219 & 0,34 & Diterima \\
\hline 6 & 2423 & 2406 & 0,35 & Diterima & 6 & 1779 & 1769 & 0,24 & Diterima \\
\hline
\end{tabular}

Berdasarkan hasil analisis menggunakan rumus statistic GEH dapat disimpulkan jika model simulasi dapat merepresentasikan keadaan lalu lintas yang sesungguhnya di lapangan. Setelah dilakukan kalibrasi, maka tahap selanjutnya adalah melakukan tahap validasi menggunakan uji paired sample t-test pada data panjang antrian maksimum setiap simpang dengan interval waktu 10 menit, dan waktu tempuh perjalanan.

Tabel 3. Hasil Uji T-test panjang antrian jam puncak

\begin{tabular}{|c|c|c|c|c|c|c|c|c|}
\hline \multirow[t]{2}{*}{ No. } & \multirow{2}{*}{$\begin{array}{c}\text { Lengan } \\
\text { Sim- } \\
\text { pang }\end{array}$} & \multirow[t]{2}{*}{ Interval Menit ke } & \multicolumn{2}{|c|}{$\begin{array}{l}\text { Panjang antrian Maksimum } \\
\text { (m) }\end{array}$} & \multirow[t]{2}{*}{$\begin{array}{c}\mathrm{T} \\
\text { hitung }\end{array}$} & \multirow[t]{2}{*}{$\begin{array}{c}\mathrm{T} \\
\text { tabel }\end{array}$} & \multirow[t]{2}{*}{$\mathbf{P}$} & \multirow[t]{2}{*}{ Keterangan } \\
\hline & & & Model & Observasi & & & & \\
\hline \multirow{6}{*}{1} & \multirow{6}{*}{ Selatan } & $07: 15: 39$ & 45 & 40 & \multirow{6}{*}{1,153} & \multirow{6}{*}{2,228} & \multirow{6}{*}{0,275} & \multirow{6}{*}{ OK } \\
\hline & & $07: 25: 39$ & 50 & 45 & & & & \\
\hline & & $07: 35: 39$ & 48 & 54 & & & & \\
\hline & & $07: 45: 39$ & 53 & 49 & & & & \\
\hline & & $07: 55: 39$ & 45 & 40 & & & & \\
\hline & & 08:05:39 & 55 & 48 & & & & \\
\hline
\end{tabular}

Tabel 4. Hasil uji T-test panjang antrian jam tidak puncak

\begin{tabular}{|c|c|c|c|c|c|c|c|c|}
\hline \multirow{2}{*}{$\begin{array}{c}\text { No } \\
\text { • }\end{array}$} & \multirow{2}{*}{$\begin{array}{c}\text { Lenga } \\
\text { n Sim- } \\
\text { pang }\end{array}$} & \multirow{2}{*}{$\begin{array}{l}\text { Interval Menit } \\
\text { ke }\end{array}$} & \multicolumn{2}{|c|}{$\begin{array}{l}\text { Panjang antrian Maksimum } \\
\text { (m) }\end{array}$} & \multirow{2}{*}{$\begin{array}{c}\mathrm{T} \\
\text { hitung }\end{array}$} & \multirow{2}{*}{$\underset{\text { tabel }}{\mathbf{T}}$} & \multirow[t]{2}{*}{$\mathbf{P}$} & \multirow{2}{*}{$\begin{array}{c}\text { Ket- } \\
\text { erangan }\end{array}$} \\
\hline & & & Model & Observasi & & & & \\
\hline \multirow{6}{*}{1} & \multirow{6}{*}{ Selatan } & $09: 13: 15$ & 45 & 40 & \multirow{6}{*}{1,153} & \multirow{6}{*}{2,228} & \multirow{6}{*}{$\begin{array}{c}0,27 \\
5\end{array}$} & \multirow{6}{*}{$\mathrm{OK}$} \\
\hline & & 09:23:15 & 50 & 45 & & & & \\
\hline & & 09:33:15 & 48 & 54 & & & & \\
\hline & & $09: 43: 15$ & 53 & 49 & & & & \\
\hline & & 09:53:15 & 45 & 40 & & & & \\
\hline & & 10:03:15 & 55 & 48 & & & & \\
\hline
\end{tabular}

Berdasarkan Tabel 3 dan Tabel 4 hasil uji keduanya memiliki nilai P kurang dari 0,05, dan nilai T table yang lebih besar dari T hitung yang berartu panjanga ntrian pada model simulasi dapat merepresentasikan keadaan panjang antrian pada kondisi eksisting. Selanjutnya dilakukan uji validasi pada waktu tempuh perjalanan atau Travel Time menggunakan uji perbedaan relatif. 
Tabel 5. Hasil Uji Relatif Waktu Tempuh Jam Puncak dan Tidak Puncak

\begin{tabular}{|c|c|c|c|c|c|c|c|c|}
\hline \multirow{3}{*}{$\begin{array}{l}\text { Lengan Sim- } \\
\text { pang }\end{array}$} & \multicolumn{3}{|c|}{ Jam Puncak } & \multicolumn{5}{|c|}{ Jam Tidak Puncak } \\
\hline & \multicolumn{2}{|c|}{ Waktu Perjalanan } & \multirow{2}{*}{$\begin{array}{l}\text { Nilai } \\
\text { Perbe- } \\
\text { daan } \\
\text { Relatif }\end{array}$} & \multirow{2}{*}{$\begin{array}{c}\text { Ket- } \\
\text { erangan } \\
\text { Observasi }\end{array}$} & \multicolumn{2}{|c|}{$\begin{array}{c}\text { Waktu Perjal- } \\
\text { anan }\end{array}$} & \multirow{2}{*}{$\begin{array}{c}\text { Nilai } \\
\text { Perbe- } \\
\text { daan } \\
\text { Relatif }\end{array}$} & \multirow{2}{*}{$\begin{array}{c}\text { Ket- } \\
\text { erangan } \\
\text { Observasi }\end{array}$} \\
\hline & Model & Observasi & & & Model & $\begin{array}{c}\text { Ob- } \\
\text { servasi }\end{array}$ & & \\
\hline Selatan-Utara & 35 & 41 & $15 \%$ & Diterima & 35,6 & 32 & $11 \%$ & Diterima \\
\hline Utara-Selatan & 32 & 37 & $14 \%$ & Diterima & 27,6 & 28 & $1 \%$ & Diterima \\
\hline
\end{tabular}

Berdasarkan nilai yang didapatkan dari hasil uji relatif pada Tabel 5., didapatkan hasil dengan nilai kurang dari sama dengan 15\%, sehingga dapat disimpulkan jika waktu tempuh pada model simulasi dan kondisi eksisting memiliki rata-rata yang sebanding atau tidak memiliki perbedaan nilai yang signifikan.

\section{Permodelan Simpang Exit Toll Kebakkramat dengan berbagai Skenario}

Setelah base model memenuhi kriteria kalibrasi dan validasi, langkah selajutnya adalah mengubahnya menjadi beberapa scenario yaitu, fase normal, dan fase Semi Actuated Controller. Untuk skenario pertama, dilakukan dengan cara mengubah fase pergerakan serta penyesuaian waktu sinyal dari early cut off menjadi fase normal. Sedangkan untuk scenario kedua, yaitu scenario Semi Actuated Controllerdidesain sedemikian rupa agar lampu hijau selalu menyala dan baru akan berganti merah apabila alat mendeteksi adanya kendaraan yang akan memasuki kaki simpang. Pada mode Semi Actuated Controller ini, waktu siklus dan hijau akan bervariasi dari setiap siklusnya bergantung pada jumlah kendaraan yang melintas pada kaki simpang tersebut. Pada lokasi Exit Toll Kebakkramat sendiri, direncanakan alat dipasang pada lengan simpang barat.

Perbandingan antara Kinerja Model Simpang Exit Toll Kebakkramat Eksisting dengan Kedua Skenario Perbandingan anatar kinerja model Simpang Exit Toll Kebakkramat eksisting dengan kedua scenario, meliputi parameter panjang antrian, tundaan, dan waktu tempuh yang disajikan dalam bentuk diagram.

\section{SIMPULAN}

Hasil penelitian ini dapat disimpulkan jika program simulasi PTV VISSIM dapat merepresentasikan dengan baik keadaan simpang eksisting melalui model simulasi yang dibuat, karena program dapat mengidentifikasi berbagai keadaan lalu lintas secara terperinci. Hasil proses modeling menunjukkan bahwa volume lalu lintas, panjang antrian, dan waktu perjalanan tidak jauh berbeda antara observasi dengan proses modeling, hal tersebut menunjukkan jika base model telah tervalidasi dan terkalibrasi sesuai dengan variable yang digunakan. Setelah melalui beberapa perubahan skenario, dapat disimpulkan jika fase eksisting (early cut off) memiliki kinerja paling baik. Sedangkan untuk skenario fase normal menghasilkan kinerja yang menurun dikarenakan adanya penurunan waktu hijau, dan pada skenario Semi Actuated Controller menghasilkan kinerja yang kurang maksimal dikarenakan pada kaki simpang barat Exit Toll Kebakkramat kerap dilewati oleh kendaraan, dimana hal tersebut berkebalikan dengan konsep sistem Semi Actuated Controller yang hanya akan bekerja secara maksimal jika berada di lokasi yang dilalui sedikit kendaraan.

\section{SARAN}

Untuk penelitian selanjutnya diharapkan dapat melakukan kalibrasi panjang antrian pada setiap cycle time agar dapat menghasilkan model yang lebih representative, dapat memodelkan Simpang Exit Toll Kebakkramat dengan system Semi Actuated Controller menggunakan pengaturan pergerakan late star. Selain itu, agar model simulasi bisa semakin merepresentasikan eksisting, pada proses pengambilan data bisa menambahkan pencatatan untuk mengetahui jumlah pengendara yang melakukan pelanggaran lalu lintas di Simpang Exit Toll Kebakkramat. Agar lebih bermanfaat, untuk penelitian selanjutnya dapat memberikan rekomendasi system pengaturan sinyal lalu lintas yang efektif dan efisien untuk Simpang Exit Toll Kebakkramat.

\section{UCAPAN TERIMAKASIH}

Penulis mengucapkan puji syukur dan terima kasih kepada Tuhan Yang Maha Esa, serta segenap pihak yang mendukung terselesaikannya, dan diterbitkannya penelitian ini. 
Jurnal Matriks Teknik Sipil DOI: https://dx.doi.org/10.20961/mateksi.v9i2.53563

ISSN: $2354-8630$

E-ISSN: 2723-4223

Vol 9, No 2 (2021): Juni

\section{REFERENSI}

Putri, Nurjannah Haryanti, dan Irawan, Muhammad Zudhy, 2015, "Mikrosimulasi Mixed Traffic pada Simpang Bersinyal dengan Perangkat Lunak VISSIM (Studi Kasus Simpang Tugu, Yogyakarta)", The 18th FSTPT International Symposium, Unila, Bandar Lampung, 28 August 2015.

Yulianto, B., 2003, “Application of fuzzy logic to traffic signal control under mixed traffic conditions”. Traffic Engineering and Control. Vol 44 No 9, pp. 332-335. 